\title{
A EDUCAÇÃO ESPECIAL E INCLUSIVA NO ENSINO DE QUÍMICA: um mapeamento de teses e dissertações no período de 2009 a 2019
}

\author{
Rafael Soares Silva \\ Carmem Lúcia Costa Amaral
}

\section{Resumo}

Esse artigo apresenta o resultado de um mapeamento de pesquisas acadêmicas com foco em Educação Inclusiva no Ensino de Química no contexto da Deficiência Visual. Para coleta de dados foram utilizadas as dissertações e teses publicadas no banco de Teses e Dissertações da Coordenação de Aperfeiçoamento de Pessoal de Nível Superior (Capes) no período de 2009 a 2019. O objetivo desse mapeamento foi conhecer como os pesquisadores da área de Ensino de Química estão desenvolvendo suas práticas com esse público. Foram encontradas 22 produções acadêmicas, sendo 2 teses e 20 dissertações. Os resultados evidenciaram que as pesquisas relacionadas a esse tema ainda se apresentam tímidas e destacam, em sua maioria, as dificuldades e os desafios dos professores em atuarem com alunos com deficiência visual.

Palavras-chave: mapeamento; educação inclusiva; ensino de química; deficiência visual.

SPECIAL AND INCLUSIVE EDUCATION IN CHEMISTRY TEACHING: a mapping of theses and dissertations in the period from 2009 to 2019

\section{Abstract}

This article presents the result of a mapping of academic research with a focus on Inclusive Education in the Teaching of Chemistry in the context of Visual Impairment. For data collection were used the catalogue of theses and dissertations of the of the Coordination for the Improvement of Higher Education Personnel (CAPES) between 2009 and 2019. The goal of this mapping was to investigate how researchers in the area of Chemistry Education are developing their practices with these students. Twenty-two academic productions were found, including 2 theses and 20 dissertations. The results showed that the research related to this theme are still incipient and it point, mostly, the difficulties and challenges of teachers in working with these students.

Keywords: mapping; inclusive education; chemistry teaching; visual impaired students.

\section{EDUCACIÓN ESPECIAL E INCLUSIVA EN LA ENSEÑANZA DE LA} QUÍMICA: un mapeo de tesis y disertaciones en el período de 2009 a 2019

\section{Resumen}

Este artículo presenta el resultado de un mapeo de la investigación académica con enfoque en la Educación Integrada en la Enseñanza de la Química en el contexto de la Discapacidad Visual. Para la recolección de datos se utilizaron disertaciones y tesis publicadas en el Banco de Tesis y Disertaciones de la Coordinación para el Perfeccionamiento del Personal de Educación Superior (Capes) en el período de 2009 a 2019. El propósito de este mapeo fue conocer cómo los investigadores de la Área de Educación de la Química están desarrollando sus prácticas con este público. Se encontraron 22 producciones académicas, incluidas 2 tesis y 20 disertaciones. Los resultados mostraron que las investigaciones relacionadas con esta temática aún están 
presentes y se destacan, en su mayoría, como las dificultades y desafíos de los docentes en el trabajo con estudiantes con discapacidad visual.

Palabras clave: mapeo; educación inclusiva; enseñanza de la química; discapacidad visual.

\section{INTRODUÇÃO}

Nos últimos anos a Educação Especial e Inclusiva é um dos temas mais discutidos no campo educacional e sua importância levou a promulgação da Lei Brasileira de Inclusão (também conhecida como Estatuto da Pessoa com Deficiência) e a sua inserção nas propostas de políticas públicas, nas leis civis e educacionais do Brasil como a Constituição Federal, a Lei de Diretrizes e Bases da Educação Nacional (LDB 9394/96), o Estatuto da Criança e do Adolescente (ECA $8.069 / 90)$ e as várias políticas de atendimento à pessoa com deficiência propostas pelo governo federal.

Entre as propostas do governo federal está o Plano Nacional de Educação (PNE), cuja meta 4 se refere à Educação Especial Inclusiva para a população de 4 a 17 anos. Desde a publicação do PNE, em 2014, verifica-se que o percentual de matrículas de alunos especiais incluídos em classe comum aumentou gradativamente ao longo dos anos. Em 2015, o percentual era de 88,4\%, em 2019 esse percentual passou para 92,8\% com 1,3 milhões de alunos. Além disso, considerando a mesma população de 4 a 17 anos, verifica-se que o percentual de alunos que estão incluídos em classe comum e que têm acesso às turmas de atendimento educacional especializado também cresceu no período, passando de 37,4\% em 2015 para 40,8\% em 2019 (INEP, 2019).

O maior número de matrículas está no Ensino Fundamental que concentra 70,8\%. Entretanto, de acordo com os dados do Instituto Nacional de Estudos e Pesquisas Educacionais Anísio Teixeira (INEP, 2019) quando avaliado o aumento no número de matrículas entre 2015 e 2019, no Ensino Médio foram as que mais cresceram, com um aumento de 91,7\%.

Do total desses alunos matriculados na Educação Básica, 80.091 são deficientes visuais, sendo 6.252 com cegueira (perda total da função visual ou pouquíssima capacidade de enxergar) e 73.839 com baixa visão (perda parcial da função visual) (INEP, 2019). Com esse número expressivo de alunos com deficiência visual matriculados nas várias etapas da Educação Básica e enquanto professor de química e pesquisador de um programa de pós-graduação em Ensino de Ciências e Matemática surgiu as seguintes indagações: como os pesquisadores da área de Ensino de Química têm desenvolvido pesquisas envolvendo esses alunos com deficiência visual? Quais temas foram mais desenvolvidos? Quais os desafios e as dificuldades de se ensinar química no contexto da deficiência visual? Para responder essas perguntas realizamos um mapeamento de teses e dissertações publicadas no portal Capes no período de 2009 a 2019. Assim, o objetivo desse artigo é apresentar o resultado desse mapeamento.

Optamos nesse artigo por tratar apenas das pesquisas em envolvem alunos com deficiência visual, pois através da visão, nos comunicamos com o mundo. Por meio dela, construímos representações, compreendemos conceitos e acompanhamos todas as transformações que ocorrem na sociedade. Como descreve Brandão (2009), a visão possibilita a apropriação de notícias, eventos, a observação dos acontecimentos. Os deficientes visuais, no entanto, ficam privados e limitados em apreender esses episódios de transferência de cultura e de conteúdo.

Pesquisas realizadas por Creppe (2009), Pires (2010), Aragão (2012), Dantas Neto (2012), Santos (2012), Melo (2013), Amazonas (2014), Silva (2014), Silva (2014), Jesus (2014), Uliana (2015), Paula (2015), Costa (2016), Perovano (2017), Lima (2017), Toledo (2017), Molena (2018), França (2018), Alves (2018), Simões (2018), Ataíde (2019), Silva (2019) dentre outros, apontam que 
os estudantes com deficiência visual podem ter desenvolvimento cognitivo semelhante aos demais colegas que não possuem alteração no sentido da visão se lhes forem proporcionados materiais pedagógicos e metodologias que permitam a eles participarem ativamente do processo, utilizandose de outros sentidos.

\section{PROCEDIMENTOS METODOLÓGICOS}

O presente estudo caracteriza-se como uma pesquisa de mapeamento que de acordo com Fiorentini et al. (2016) é um processo sistemático de levantamento e descrição de informações acerca das pesquisas produzidas sobre um campo específico de estudo, abrangendo um determinado espaço e período de tempo. A coleta de dados foi realizada no Banco de Teses e Dissertações da Capes referentes ao Ensino de Química para o aluno com deficiência visual. O período escolhido foi de 2009 a 2019.

Os descritores para a busca no portal da Capes foram: "Ensino de Química + deficiente visual", "Ensino de Química + Inclusão", "Ensino de Química + alunos cegos", "Química + Inclusão", "Ensino de Química + Educação Especial", "Ensino de Química Inclusiva", "Química + cegos" e "Ensino de Química + braille".

Com essa busca encontramos 28 pesquisas, entre teses e dissertações que tratavam do Ensino de Química no contexto da Educação Especial de forma geral. Entretanto, como nosso objetivo estava voltado ao aluno com deficiência visual, esse número foi reduzido para 22 pesquisas que foram lidas integralmente.

Seguindo as orientações de Fiorentini et al. (2016), organizamos os dados para estabelecer focos. Para isso iniciamos realizando a leitura de cada pesquisa para obter as informações gerais e específicas na forma de itens: título, autores, linha de pesquisa, local e ano de publicação, instituição de origem, objetivo(s), referencial teórico, processo metodológico, resultados e contribuição para a área. A partir dessas informações definimos 2 focos temáticos e 3 subfocos. Um foco temático no professor com 2 subfocos e o outro no aluno com somente um subfoco, conforme pode ser observado no Quadro 1.

Quadro 1 - Distribuição dos focos e subfocos das produções pesquisadas.

\begin{tabular}{|l|l|}
\hline \multicolumn{1}{|c|}{ Focos Temáticos } & \multicolumn{1}{c|}{ Subfocos } \\
\hline 1- Foco no Professor & 1.1 - Proposta de intervenção \\
& 1.2. - Percepção \\
2- Foco no Aluno & 2.1 - Ferramentas para Aprendizagem \\
& \\
\hline
\end{tabular}

Fonte: Os autores

Santos (2015) aponta que a categorização de um trabalho em focos temáticos é um processo complexo e que exige um olhar atento, especialmente pela multiplicidade de enfoques, abordagens e metodologias que geralmente se manifestam no conjunto de trabalhos pesquisados. Os subfocos especificam, dentro de cada foco temático, o objeto de estudo dos trabalhos. Buscamos com esses subfocos uma delimitação mais clara entre os focos, e uma melhor definição estabelecida dentro de cada foco. 


\section{RESULTADOS E DISCUSSÃO}

\section{Informações Gerais encontradas nas produções acadêmicas}

Como citado anteriormente, foram selecionadas 22 produções acadêmicas, sendo 20 dissertações e 2 teses como pode ser observado na Tabela 1.

Tabela 1 - Número de produções acadêmicas selecionadas.

\begin{tabular}{lc|c}
\multicolumn{1}{c|}{$\begin{array}{c}\text { Características dos } \\
\text { trabalhos }\end{array}$} & Número & Porcentagem (\%) \\
\hline Tese (Doutorado) & 2 & 9 \\
Mestrado (acadêmico) & 18 & 82 \\
Mestrado (profissional) & 2 & 9 \\
\hline
\end{tabular}

Fonte: os autores.

Os dados apresentados nessa tabela mostram um número pequeno de trabalhos. Considerando o aumento do número de alunos com deficiência visual matriculados na educação básica e por ser a escola um lugar de pesquisa, conhecimento e inclusão social, além do crescimento de programas de pós-graduação na área de educação esperávamos encontrar um número maior de trabalhos. Entretanto, isto não ocorreu sinalizando o que descreve Mantoan (2007):

[....] ainda há muita resistência. Problemas conceituais, desrespeito a preceitos constitucionais, interpretações tendenciosas de nossa legislação educacional e preconceitos que distorcem o sentido da inclusão escolar são também grandes barreiras a serem enfrentadas pelos que defendem essa inclusão (MANTOAN, 2007, p. 18).

Analisando essas produções em termos de publicação por ano e por instituição observamos que houve um pequeno crescimento de pesquisas ao longo do período pesquisado (2009-2019), e que estas pesquisas foram oriundas de universidades públicas. Uma explicação para esse resultado deve-se ao fato dessas instituições de ensino apresentarem, como descrevem Ferreira e Amaral (2015) condições que propiciam o desenvolvimento dessas pesquisas, como: professores pesquisadores em regime de dedicação exclusiva; boa infraestrutura; apoio financeiro das próprias universidades e de órgãos de fomento à pesquisa e grupos de pesquisa consolidados. 
O gráfico 2 mostra a distribuição das produções por região.

Gráfico 02. Distribuição das produções acadêmicas por região.

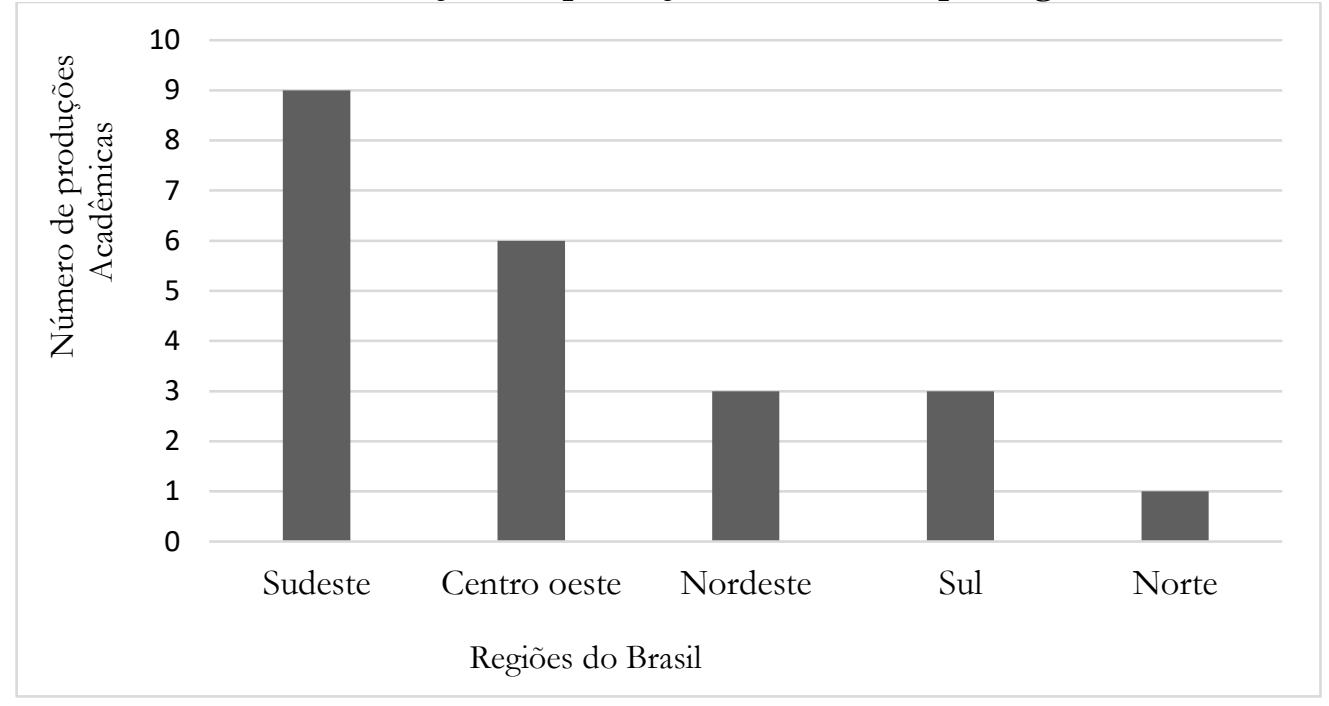

Fonte: Os autores

De acordo com esse gráfico, a região Sudeste concentra o maior número de pesquisas, com destaque para a Universidade Federal de São Carlos com quatro produções, sendo uma tese de doutorado e três pesquisas a nível de mestrado acadêmico. A Universidade do Grande Rio com duas pesquisas de mestrado acadêmico, seguida da Universidade Federal do Espírito Santo e Universidade Estadual Paulista, cada uma com uma pesquisa a nível de mestrado acadêmico. Ainda na região Sudeste encontramos uma pesquisa de mestrado profissional na Universidade Federal de Minas Gerais.

$\mathrm{Na}$ região Centro-Oeste das seis produções, quatro foram desenvolvidas na Universidade de Brasília, três pesquisas de mestrado acadêmico e uma de mestrado profissional, uma na Universidade Federal do Mato Grosso (nível doutorado) e uma pesquisa de mestrado acadêmico na Universidade Federal de Goiás. Na região Norte somente a Universidade do Estado do Amazonas apresentou uma produção a nível de mestrado acadêmico. $\mathrm{Na}$ região Nordeste destacam-se a Universidade Federal do Ceará com uma dissertação de mestrado acadêmico e a Universidade Estadual da Paraíba com duas pesquisas a nível de mestrado acadêmico e na região Sul cada produção de mestrado acadêmico foi desenvolvida em uma instituição de ensino diferente, sendo elas, Universidade do Vale do Taquari (RS), Universidade Federal do Paraná e na Universidade Estadual de Maringá.

Essas pesquisas evidenciam que é possível ensinar conceitos e fenômenos químicos a alunos com deficiência visual, mesmo com as dificuldades que perpassam esse processo. Entre essas dificuldades estão a necessidade da formação docente, a elaboração de recursos especiais, uso de metodologias apropriadas para atender às necessidades, condições de trabalho docente, adaptações experimentais, em que muitas vezes os fenômenos são explicados a partir de observações visuais e aplicação das três dimensões do conhecimento químico, sendo os níveis teórico, fenomenológico e representacional (MOLENA, 2018). 
Informações específicas encontradas nas produções acadêmicas

O gráfico 3 apresenta os focos e subfocos relacionados as pesquisas envolvendo o Ensino de Química com alunos com deficiência visual.

Gráfico 03. Focos e subfocos relacionados as pesquisas.

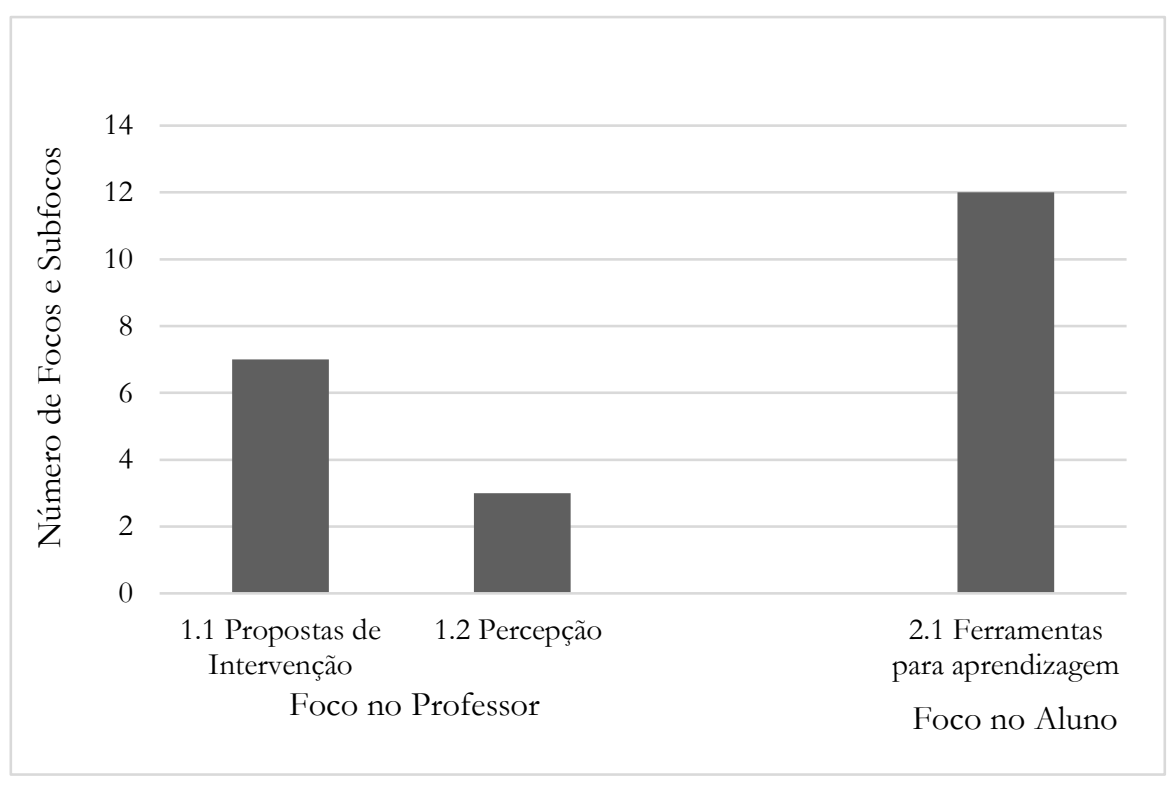

Fonte: Os autores

A partir desse gráfico podemos observar dez produções para o foco que trata do professor, sete com propostas para auxiliá-lo no Ensino de Química com alunos com deficiência visual e três que envolvem suas concepções. É possível constatarmos também que das 22 pesquisas mapeadas doze possuem foco no aluno, com estratégias didáticas e/ou propostas metodológicas de ensino para alunos com deficiência visual.

\section{Foco no professor: Propostas de Intervenção}

A formação didático-pedagógica do professor foi a preocupação de sete trabalhos que, em sua maioria visam apoiar a prática pedagógica de professores de química em sala de aula inclusiva no contexto da deficiência visual. Nesse foco encontram-se as pesquisas desenvolvidas por Pires (2010), Dantas Neto (2012), Uliana (2015), Melo (2013), França (2018), Alves (2018) e Simões (2018).

Pires (2010) descreve o desenvolvimento de um material para apoiar a prática pedagógica de professores da Educação Básica que tenham alunos com deficiência visual em sua sala de aula. Embora aborde questões metodológicas mais voltadas para a disciplina de Química, seu conteúdo geral também pode ser utilizado por professores de qualquer disciplina.

Dantas Neto (2012), adaptou algumas atividades experimentais apresentadas no livro didático Química Cidadã para que os professores as desenvolvam com seus alunos deficientes visuais durante as aulas. 
Uliana (2015), investigou como uma disciplina/curso de formação de futuros professores de Matemática, Física e Química, centrada em estratégias de ensino para estudantes com deficiência visual pode contribuir para a preparação docente, tendo em vista a promoção do ensino inclusivo.

Melo (2013) promoveu ações colaborativas entre uma professora de química e uma professora de Educação Especial de uma escola polo do interior paulista que atende alunos com deficiência visual. A professora de química nunca havia lecionado para esta população. A parceria da professora de química com a professora de Educação Especial teve como resultado a adaptação de materiais para intervenção em sala de aula.

França (2018), investigou as contribuições da parceria colaborativa universidade/escola como proposta formativa de professores para a inclusão escolar. De acordo com o autor essa parceria pode ser uma alternativa para a melhoria da qualidade do ensino inclusivo nas salas de aulas regulares, pois é necessário que o professor se aproprie de conhecimentos epistemológicos que fundamentam o ensino inclusivo para atuar como mediador nesse processo, contribuindo para que o aluno deficiente visual tenha mais autonomia na sua aprendizagem.

Alves (2018), desenvolveu um minicurso com uma turma de licenciatura em Química e nesse minicurso abordou alguns aspectos sobre o Ensino de Química para pessoas com deficiência visual. Seu minicurso envolveu as seguintes etapas: reflexão de conceitos históricos e legislativos em torno da deficiência visual, discussão e exemplificação da metodologia multissensorial e aplicação de aulas temáticas elaboradas pelos licenciandos para os alunos com deficiência visual que frequentam sala de apoio. Essa aplicação foi possível porque o minicurso foi desenvolvido na disciplina de Estágio.

Simões (2018), desenvolveu uma website como ferramenta de apoio na elaboração de atividades do professor. Para esse autor, a website auxiliou os professores na construção de materiais pedagógicos e diminuiu as barreiras existentes entre alunos videntes e alunos com deficiência visual. No site o professor teve acesso a diferentes recursos didáticos como a grafia química braile, artigos que descrevem os processos de elaboração e construção de tabelas periódicas e materiais didáticos que abordam o modelo de representação visual.

\section{Foco no professor: Concepções Docente}

Três pesquisas analisaram as crenças, as concepções, as atitudes ou as representações de futuros professores de Química no contexto da deficiência visual. Essas pesquisas foram desenvolvidas por Paula (2015), Molena (2018) e Ataíde (2019).

Paula (2015), analisou as necessidades formativas de professores de Química para inclusão de alunos com deficiência visual. O resultado de sua pesquisa evidenciou, segundo a autora, que a formação dos professores deve fornecer os subsídios necessários para o docente trabalhar as diferenças em sala de aula, pois a autora acredita que, com isso, o professor terá condições de organizar o currículo, de propor metodologias e formas de avaliação diferenciadas para alunos videntes e não videntes

Molena (2018), identificou as percepções de professores de Química atuantes no Ensino Médio em salas de aulas regulares e professores em formação inicial quanto ao processo de conceitualização por parte dos alunos com deficiência visual. Os resultados de sua pesquisa mostraram que esses professores entendiam a importância de ensinar conceitos e fenômenos químicos a alunos com deficiência visual e apontaram dificuldades que perpassam esse processo. Entre essas dificuldades a autora apontou a necessidade da formação docente, de elaboração de recursos especiais, desenvolvimento de metodologias apropriadas para atender às necessidades dos alunos com deficiência visual, condições de trabalho docente, adaptações experimentais, uma vez 
que em geral os fenômenos são explicados a partir de observações visuais, e aplicação das três dimensões da especificidade do conhecimento químico: os níveis teórico, fenomenológico e representacional.

Ataíde (2019), investigou as dificuldades de um professor de Química para ensinar para uma aluna cega. Ela apontou várias dificuldades, entre elas, a preparação do professor em buscar novos meios para facilitar o processo de ensino e aprendizagem como a adaptação de materiais e a utilização de recursos pedagógicos voltados para esse público. Uma observação descrita em sua pesquisa é que não houve interação da aluna cega com o professor, era como se a aluna não estivesse na sala e todas as informações ou orientações do professor foram realizadas com o ledor. Da mesma forma, a interação entre a aluna e o ledor foi praticamente inexistente. O ledor usava termos técnicos para falar com a aluna e só falava o que é necessário.

\section{Foco no Aluno: Ferramentas para Aprendizagem}

Neste tema, estão reunidas pesquisas que apresentam estratégias didáticas e/ou propostas metodológicas de ensino dos conteúdos de Química para alunos com deficiência visual. As pesquisas com esse foco foram desenvolvidas por Creppe (2009), Aragão (2012), Santos (2012), Amazonas (2014), Jesus (2014), Silva (2014a), Silva (2014b), Costa (2016), Toledo (2017), Perovano (2017), Lima (2017) e Silva (2019).

Em seu estudo Creppe (2009) investigou sujeitos que apresentavam Deficiência Visual adquirida, focando-se nas dificuldades encontradas, dentre estas a ausência de Materiais Didáticos Adaptados (MDAs) para um melhor entendimento de conceitos químicos. Foi utilizado o modelo molecular, escolhido pelos sujeitos (Molecular Visions), como facilitador à compreensão da tridimensionalidade de algumas moléculas orgânicas.

Aragão (2012), aponta que a utilização de modelos no Ensino de Química vem atrelando o entendimento de vários conteúdos à significação visual. Assim, torna-se essencial compreender como os alunos cegos podem aprender os conceitos de Química, uma vez que estes estão vinculados com as questões sociais nas quais os indivíduos estão envolvidos. Para entender o contexto de participação escolar desses alunos nas aulas de Química, foram entrevistados os alunos com deficiência visual de duas classes do primeiro ano do Ensino Médio, de uma escola estadual de uma cidade do interior do estado de São Paulo, seus professores de Química e a professora da sala de recursos. Os resultados contribuíram para a elaboração de um material didático-pedagógico com o objetivo de proporcionar ferramentas para esses alunos na apropriação dos conceitos químicos.

Santos (2012), construiu uma página na web adaptada a alunos com deficiência visual na perspectiva de favorecer a inclusão escolar e digital, uma vez que a maioria dos sites não permite uma navegação fácil para esses estudantes.

Amazonas (2014), em seu estudo utilizou fórmulas de substâncias químicas expressas em Braille confeccionadas com materiais alternativos, de diferentes formatos e tamanhos, metalizados e de plástico em alto relevo, resultando numa texturização, objetivando auxiliar na compreensão de conteúdos de Química, por alunos com deficiência visual de diferentes especificidades clínicas. Esses materiais foram apresentados a seis alunos com deficiência visual matriculados na Unidade São Cristóvão III, onde durante nove encontros puderam analisar diferentes texturas no sentido de avaliar qual seria o material mais apropriado para a confecção dos mesmos.

Silva (2014a), buscou entender as vantagens e limitações do uso de jogos no Ensino de Química. Para isso, o autor elaborou um jogo com estruturas de moléculas envolvidas em situações problemas, o qual, de acordo com o autor, possibilitou abordar questões relacionadas às 
proporções envolvidas nas reações químicas. Ainda segundo o autor, seu jogo apresenta uma proposta educacional com vistas não só à inclusão de alunos com deficiência visual em turmas inclusivas, pois trata do assunto de maneira a possibilitar o aprendizado de todos os alunos. Videntes e não videntes.

Silva (2014b) analisou como as Tecnologias assistivas utilizadas no Centro de Apoio Pedagógico para Atendimento à Pessoa com Deficiência Visual de Boa Vista (Roraima), contribuem para a aprendizagem dos conteúdos de Química no Ensino Médio. Os resultados de sua pesquisa evidenciou que as Tecnologias asssitivas utilizadas nesse Centro contribui para o desenvolvimento dos conhecimentos de química dos alunos com deficiência visual de forma igualitária e dinâmica.

Jesus (2014), analisou as contribuições de modelos atômicos alternativos no processo de ensino e aprendizagem das moléculas de hidrocarbonetos nos conteúdos de Química a alunos com deficiência visual. O autor construiu maquetes dos modelos atômicos de Dalton, Thomson, Rutherford e Rutherford-Bohr, modelos atômicos alternativos dos átomos de carbono e hidrogênio, que foram posteriormente utilizados na construção das maquetes. O objetivo do autor foi oferecer a esses estudantes uma ferramenta pedagógica tátil. O resultado de sua pesquisa mostrou que a construção da maquete os auxiliou na apropriação desses saberes.

Costa (2016) observou a formação de conceitos científicos para sujeitos com deficiência visual ao utilizar a Sequência Fedathi como aporte metodológico para o Ensino da Química. A aplicação da Sequência Fedathi, teve como propósito mudanças na forma como os professores conduzem suas aulas. De acordo com o autor, embora a Sequência Fedathi tenha sido desenvolvida com ênfase na Matemática, a mesma pode ser usada em qualquer outra disciplina.

Toledo (2017), coletou, avaliou e disseminou vários estudos, com foco na Educação Química para alunos com deficiência visual, por meio da revisão sistemática da literatura. Os resultados apontaram que existem lacunas de pesquisa acerca da temática, apesar dos esforços realizados pelos pesquisadores. Exemplos de trabalhos práticos foram realizados, apresentados e discutidos. Para que o ensino de Química atinja a todos os alunos com a devida equidade, o professor deve estar preparado, garantindo qualidade no ensino que está sendo proporcionado.

Perovano (2017), elaborou recursos didáticos para o ensino de Química a estudantes cegos, uma vez que constatou uma carência de recursos didáticos adequados às necessidades educacionais desses alunos e isso configura-se como uma barreira de acesso a diversos conteúdos no processo de ensino-aprendizagem de Química. Neste contexto, surgiu a necessidade da autora adotar estratégias didáticas capazes de assegurar que os elementos curriculares fossem acessíveis a estes alunos.

Lima (2017), em sua pesquisa aborda a necessidade de um novo pensar frente ao processo de ensino e aprendizagem dos conteúdos de Química para alunos com deficiência visual que estão inseridos na escola regular, mas, que em muitos momentos, não tem acesso ao conhecimento científico por falta de adaptações curriculares e metodológicas. No tocante ao Ensino de Química, que se apresenta como uma disciplina que exige interação com gráficos, modelos e imagens, para a autora é nas adaptações de materiais didáticos e na formação continuada dos professores que estão às condições necessárias para garantir uma real inclusão dos alunos com deficiência visual nas aulas.

Silva (2019), teve como foco em sua pesquisa a interação de um aluno cego com livro didático em formato Daisy fornecido pela rede pública de ensino. $O$ autor analisou as potencialidades do áudio descrição deste livro na abordagem dos conceitos de substância simples e composta. O resultado de sua pesquisa evidenciou a dificuldade do estudante na leitura do material devido a deficiência do repertório simbólico, que é fornecido pelo professor. 


\section{CONSIDERAÇÕES FINAIS}

O resultado desse mapeamento evidenciou que nos últimos dez anos as pesquisas sobre a Educação Especial e Inclusiva no Ensino de Química envolvendo alunos com deficiência visual, apesar de um crescimento, ainda se apresentam tímidas. O que se percebe é que ainda é um tabu trabalhar com alunos que possuem necessidades educacionais especiais.

As pesquisam sugerem, em sua maioria metodologias, estratégias, jogos para facilitar o processo de ensino-aprendizagem no contexto da deficiência visual. Entretanto, essas contribuições parecem não sair dos lócus das pesquisas, ou seja, não chegam ou alcançam as salas de aula no dia-a-dia, principalmente quando se trata do Ensino de Química.

Como focos de pesquisa de maior interesse, encontramos a formação, aprendizagem e desenvolvimento profissional do professor que ensina química para alunos com deficiência visual, seguido de atitudes, crenças, concepções, saberes e competências desse profissional para ensinar esse público. As pesquisas com foco no aluno estão centradas no uso de ferramentas estratégias didáticas e/ou propostas metodológicas de ensino dos conteúdos de Química.

Como pontua Ataíde (2019), não é tão distante da realidade do professor ou da instituição proporcionar ao aluno cego formas de aprender os conteúdos de Química. Pequenas mudanças nas práticas educativas podem fazer uma grande diferença para a aprendizagem do aluno. $\mathrm{O}$ professor pode procurar meios de conhecer melhor o assunto e buscar novas formas de fazer acontecer a inclusão de um aluno cego em sua sala de aula. Para isso ele deve falar de forma pausada em suas aulas, tentando descrever ao máximo o que está sendo exposto, ter o cuidado de interagir e integrar esse aluno a suas aulas, tentar fazer com que outros alunos também tenham interação com o aluno cego.

O professor deve tentar envolver os demais alunos ao processo de inclusão e evitar ao máximo as expressões direcionadas exclusivamente aos videntes, como "vejam aqui", "estão vendo", "como vocês podem ver", entre outras. Como podemos observar, alguns aspectos podem contribuir para a melhoria da aprendizagem dos conceitos de química para alunos com deficiência visual, dentre eles: adaptação de material, qualificação profissional e o uso da grafia química braile para uso no Brasil. Segundo Bertalli (2010, p. 37):

Há poucos grupos que trabalham o ensino de química para deficientes visuais no Brasil. Nos últimos dez anos há apenas cinco resumos 38 apresentados na Reunião Anual da Sociedade Brasileira de Química (RASBQ) e quatro no Encontro Nacional de Ensino de Química (ENEQ) (BERTALLI, 2010, p. 37).

Nessa perspectiva, o docente, para ensinar Química deve mediar os conhecimentos dos estudantes criando ideias e sugerindo a exploração dessas, fomentando o processo de ensino através da investigação. Como apontam Barbosa (2006) e Brandão (2009), um fator essencial para que alunos com deficiência visual obtenham êxito na aprendizagem é que os docentes procurem utilizar recursos mais apropriados a esses alunos. Assim, a atividade vai exigir do docente discernir sua prática além da deficiência, notando que existem características específicas no desenvolvimento de todos os alunos, sendo eles videntes ou não.

Como sugere Dantas Neto (2012) o aluno com deficiência visual necessita de materiais adaptados que sejam adequados ao conhecimento tátil-cinestésico, auditivo, olfativo e gustativo. A adequação de materiais, sejam eles os roteiros experimentais ou qualquer outro, tem a intenção de proporcionar as mesmas informações as quais outros estudantes tem acesso, permitindo, dessa forma, que o aluno com deficiência visual não fique em desvantagem quanto ao acesso ao conhecimento trabalhado na escola. 
Espera-se que os resultados deste mapeamento possam propiciar e subsidiar reflexões, discussões e realização de novos estudos, principalmente suscitar mudanças acerca da realidade do processo de in/exclusão que os alunos com deficiência visual estão vivenciando nas escolas brasileiras.

\section{REFERÊNCIAS}

ALVES, Fernanda Iassenck de Matos. Ensino de química para alunos com deficiência visual: subsídios teóricos e práticos. 235 f. Dissertação (Mestrado em Educação para a Ciência e a Matemática) - Universidade Estadual de Maringá, Maringá, 2018.

ATAÍDE, Katia Fabiana Pereira de. Ensino de Quimica com aluno cego: Desafios do professor, dificuldades na aprendizagem. 125f. Dissertação (Mestrado em Ensino de Ciências e Educação Matemática) Universidade Estadual da Paraíba, Campina Grande, 2019.

AMAZONAS, Jackline Torres. Quimica através dos sentidos: texturização de fórmulas para alunos com deficiência visual. 194 f. Dissertação (Mestrado em Ensino das Ciências na Educação Básica) Universidade do Grande Rio "Prof. José de Souza Herdy", Duque de Caxias, 2014.

ARAGÃO, Amanda Silva. Ensino de química para alunos cegos: desafios no ensino médio. $122 \mathrm{f}$. Dissertação (Mestrado em Ciências Humanas) - Universidade Federal de São Carlos, São Carlos, 2012.

INEP. INSTITUTO NACIONAL DE ESTUDOS E PESQUISAS EDUCACIONAIS ANÍSIO TEIXEIRA. Sinopse Estatística da Educação Básica, 2019. Brásília: INEP, 2019. Disponível em: http://portal.inep.gov.br/sinopses-estatisticas-da-educacao-basica. Acesso em: 23 mar. 2020.

BRASIL. Estatuto da Criança e do Adolescente no Brasil. Lei n. 8.069, de 13 de julho de 1990.

BRASIL. Ministério da Educação. Lei de Diretrizes e Bases da Educaşão Nacional. LDB No9.394 de 20 de dezembro de 1996.

BRANDÃO, Jorge. Vivenciando a Matemática, São Paulo: Scortercci, 2009.

BARBOSA, Paula Marcia. A importância do pensamento visual na Geometria. In: VI Seminário de Pesquisa em Educaşão Matemática do Estado do Rio de Janeiro, 2006. Rio de Janeiro- RJ. Anais do VI SPEM. 2006.

BERTALLI, Jucilene Gordin. Ensino de geometria molecular, para alunos com e sem deficiência visual, por meio de modelo atômico alternativo. 70f. Dissertação (Mestrado em Ensino de Ciências) - Fundação Universidade Federal de Mato Grosso do Sul, Campo Grande - MS, 2010.

BOGDAN, Robert; BIKLEN, Sari Knopp. Investigação qualitativa em Educação: uma introdução à teoria e aos métodos. Porto: Porto Editora, 1994.

CREPPE, Carlos Henrique. Ensino de química orgânica para deficientes visuais empregando modelo molecular. 106 f. Dissertação (Mestrado em Ensino das Ciências) - Universidade do Grande Rio, Duque de Caxias, 2009.

COSTA, Emilia Lima da. A formação de conceitos científicos para sujeitos com deficiência visual: sequência Fedathi como aporte metodológico no ensino de química. 78f. Dissertação (Mestrado em Educação) - Universidade Federal do Ceará, Fortaleza, 2016.

DANTAS NETO, Joaquim. A experimentação para alunos com deficiência visual: proposta de adaptação de um livro didático. 86 f. Dissertação (Mestrado em Ensino de Ciências) —Universidade de Brasília, Brasília, 2012. 
FERREIRA, Heloisa Helena Jesus; AMARAL, Carmem Lúcia Costa. Pesquisa em ensino de Química experimental: mapeamento das teses e dissertações apresentadas no Brasil de 2002 a 2011. R. Bras. de Ensino de C\&T, v.8, n. 1, n. p.20-35, 2015.

FIORENTINI, Dario et al. O professor que ensina matemática como campo de estudo: concepção do projeto de pesquisa. In: FIORENTINI, Dario; PASSOS, Carmem Lúcia Brancaglion; LIMA, Rosana Catarina Rodrigues (Org.). Mapeamento da pesquisa acadêmica brasileira sobre o professor que ensina matemática: período 2001 - 2012. Campinas, SP: FE/UNICAMP, 2016. p. 17 - 42.

FRANÇA, Fernanda Araújo. A formação docente em química para a inclusão escolar: a experimentação com alunos com deficiência visual. 117 f. Dissertação (Mestrado em Educação em Ciências e Matemática). Universidade Federal de Goiás, Goiânia, 2018.

JESUS, Raine Luiz de. O ensino de química através de maquetes didáticas de estruturas moleculares a estudantes com deficiência visual de uma escola pública de Manaus. 112 f. Dissertação (Mestrado em Educação e Ensino de Ciências na Amazônia) - Universidade do Estado do Amazonas, Manaus.

LIMA, Bruna Tayaneda Silva. Proposta de Quimica Orgânica para alunos com deficiência visual: desenhando prática pedagógica inclusiva. 172f. Dissertação (Mestrado em Ensino de Ciências e Educação Matemática) - Universidade Estadual da Paraíba, Campina Grande, 2017.

MANTOAN, Maria Teresa Eglér. Igualdade e diferenças nas escolas: olhares de futuras pedagogas. Campinas, SP: FE/UNICAMP, 2007.

MOLENA, Juliane Cristina. Ensino de química para alunos com deficiência visual: investigando a percepção de professores sobre o processo de conceitualização. 158 f. Dissertação (Mestrado em Educação em Ciências e Matemática) - Universidade Federal de São Carlos, São Carlos, 2018.

MELO, Érika Soares de. Açoes colaborativas em contexto escolar: desafios e possibilidades do ensino de química para alunos com deficiência visual. 139 f. Dissertação (Mestrado em Ciências Humanas) - Universidade Federal de São Carlos, São Carlos, 2013.

PAULA, Tatiane Estácio de. Um estudo sobre as necessidades formativas de professores de química para a inclusão de alunos com deficiência visual. 409 f. Dissertação (Mestrado em Educação em Ciências e em Matemática) - Universidade Federal do Paraná, Curitiba, 2015.

PEROVANO, Lais. Desenvolvimento de recursos didáticos para alunos cegos: um estudo de caso no ensino de reações químicas. 143f. Dissertação (Mestrado em Ensino na Educação Básica) - Universidade Federal do Espírito Santo, Espírito Santo, Vitória, 2017.

PIRES, Rejane Ferreira Machado. Proposta de guia para apoiar a prática pedagógica de professores de química em sala de aula inclusiva com alunos que apresentam deficiência visual. $158 \mathrm{f}$. Dissertação (Mestrado Profissional em Ensino de Ciências) - Universidade de Brasília, Brasília, 2010.

SANTOS, Rodrigo Medeiros dos. Estado da arte e história da pesquisa em Educação Estatística em programas brasileiros de pós-graduação. 348f. Tese (Doutorado em Educação) - Universidade Estadual de Campinas, Campinas, 2015.

SIMÕES, Guilherme Soares. Me ajuda a entender: website como ferramenta de apoio para professores no ensino de Química a estudantes com deficiência visual. 127f. Dissertação (Mestrado em Ensino de Ciências) Universidade Federal de Minas Gerais, Belo Horizonte, 2018.

SANTOS, Grazielle Alves dos. Página web com conteúdos de química acessiviel a estudantes com deficiência visual. 103f. Dissertação (Mestrado em Ensino de Ciências) -Universidade de Brasília, Brasília, 2012. 
SILVA, Laianna de Oliveira. Proposta de um jogo didático para ensino de estequiometria que favorece a inclusão de alunos com deficiência visual. 98f. Dissertação (Mestrado Profissional em Ensino de Ciências)Universidade de Brasília, Brasília, 2014a.

SILVA, Tânia Núsia da Costa. Deficiente visual: ensinando e aprendendo química através das tecnologias assistivas no Ensino Médio. 112f. Dissertação (Mestrado em Ensino de Ciências Exatas) - Universidade do Vale do Taquari - Univates, Lajeado, 2014b.

SILVA, Larissa Vendramini da. Inclusão escolar para alunos cegos: acessibilidade ao conceito de Substância em um livro didático de Química em formato Daisy. 151f. Dissertação (Mestrado em Educação para a Ciência) - Faculdade de Ciências da Universidade Estadual Paulista, Bauru, 2019.

TOLEDO, Juliana Barretto de. Ensino de química para pessoas com deficiência visual: um estudo por meio da revisão sistemática. 121f. Tese (Doutorado em Química) - Universidade Federal de São Carlos, São Carlos, 2017.

ULIANA, Marcia Rosa. Formação de professores de matemática, física e química na perspectiva da inclusão de estudantes com deficiência visual: análise de uma intervenção realizada em Rondônia. 313 f. Tese (Doutorado em Educação em Ciências e Matemática) - Universidade Federal do Mato Grosso, Cuiabá, 2015.

\section{Informações do(a) autor(a)}

Rafael Soares Silva

Universidade de São Paulo - USP

E-mail: rafael.soares@usp.br

ORCID: https://orcid.org/0000-0001-9994-6653

Link Lattes: http://lattes.cnpq.br/0828666762650747

Carmem Lúcia Costa Amaral

Universidade Cruzeiro do Sul

E-mail:carmem.amaral@cruzeirodosul.edu.br

ORCID: https://orcid.org/0000-0002-6495-153X

Link Lattes: http://lattes.cnpq.br/7715277135138074 